\title{
Publication and Privacy: Science and Sorcery?
}

\author{
"See my thoughts and feelings fill the paper, \\ seems l'll never, never really know \\ why when other people talk and chatter, \\ I would rather, rather write a song" ${ }^{\prime \prime}$
}

"Publish or perish," the battlecry of modern academia, may well be perceived by some as a call to bare their deepest and darkest secrets. Indeed, "publication" (from the Middle English publicacioun, from Middle French publication, from Latin publication-, publicatio, from publicare, from publicus public) $)^{2}$ literally means "to make public," confronting the comfortable secrecy and seclusion associated with privacy. $^{3}$

The distinction between publication and privacy also distinguishes science from sorcery. The scientist-scholar engages in the act or process of publishing observations for all to see, while the sorcerer strives to secure secrets and spells from prying eyes. While scientific observation and magical thinking about natural forces and their control may not always differ much, the manner by which the former are made available to public scrutiny and question, testing and replication, rebuttal or verification, distinguish one brand of "truth" from the other. In this vein, invoking the latter anecdotally or under the guise of authority may smack of mere sorcery.

In contemporary terms, interesting cases and trends, personal clinical observations and innovations and such other accumulations of wisdom, can well be kept to oneself, recorded in private, or shared with a small circle of colleagues or trainees. Unless these are brought to light and published, they do not join the scholarly stream, and will neither contribute to, nor benefit from true science.

\footnotetext{
'Lapeña JF, "I'd rather write a song" [unpublished song] Manila; 1979.

2publication. (2009). In Merriam-Webster Online Dictionary. Retrieved October 20, 2009, from http://www.merriam-webster.com/dictionary/publication.

${ }_{3}^{3}$ privacy. (2009). In Merriam-Webster Online Dictionary. Retrieved October 20, 2009, from http://www.merriam-webster.com/dictionary/privacy.

${ }^{4}$ Publish, Not Perish: The Art and Craft of Publishing in Scholarly Journals. University of Colorado 2006. Available from http://www.publishnotperish.org Accessed 24 April 2008.
}

Instead, they may well perpetuate an internally-consistent, albeit inaccurate or downright false, view of reality. Exposing one's ideas and words to possible rejection or revision by the judges and jury of editors and reviewers, not to mention readers, is no easy task either, but it is only by making ideas public that scientists gain the opportunity to dialogue, build on each other's contributions and join the documented and ongoing history of their field. ${ }^{4}$

Publication also has other rewards, not the least of which is academic promotion and tenure. We particularly challenge PSOHNS Fellows to set the example by publishing and leading the way for our diplomates and residents.

It gives me great pleasure to announce that The Singapore Declaration on Equitable Access To Health Information In The Western Pacific Region was adopted during the Second Joint Meeting of the Asia Pacific Association of Medical Journal Editors (APAME) and the Western Pacific Region Index Medicus (WPRIM) convened by the World Health Organization on the occasion of the $50^{\text {th }}$ Anniversary of the Singapore Medical Journal.

It was launched at the International Forum on Academic Medical Publishing on November 6, 2009 organized jointly by the Singapore Medical Journal (SMJ) and National Cancer Centre Singapore (NCC), with the support of the Singapore Medical Association (SMA) and Asia Pacific Association of Medical Journal Editors (APAME). The Declaration is simultaneously reproduced in full as a Special Announcement in several regional journals.

José Florencio F. Lapeña, Jr. M.A., M.D. 